\title{
Illuminance affects epidemiological parameters of banana Yellow Sigatoka in Brazil
}

Djalma M. Santana-Filho ${ }^{1,2}$, Milene C. da Silva ${ }^{2}$, Jorge T. de Souza ${ }^{3}$, Zilton J. M. Cordeiro ${ }^{4}$, Hermínio S. Rocha $^{4}$ and Francisco F. Laranjeira ${ }^{4}$

\footnotetext{
1 Instituto Federal de Educação Ciência e Tecnologia Baiano (current address);

2 Universidade Federal do Recôncavo da Bahia (UFRB);

3 Universidade Federal de Lavras, 37200-Lavras, MG, Brazil.

${ }^{4}$ Embrapa Cassava\&Fruits, Cruz das Almas, Bahia, Brazil, CP007, 44380-000; Corresponding author: Francisco F. Laranjeira

Email: francisco.laranjeira@embrapa.br
}

Significance and Impact of the Study: Yellow Sigatoka (Pseudocercospora musae) is a banana disease that can cause severe damage if left uncontrolled. Its control is based mostly on fungicides. Our results show that shading downregulates the epidemiological parameters of that disease such as incubation, latent and infectious periods, and symptom's severity. These results can be the basis for testing alternative cropping systems and producing organic bananas.

Keywords: Latent period, incubation period, infection, light, Mycosphaerella musicola, Pseudocercospora musae

\section{ABSTRACT}

The Sigatoka leaf spots are among the most important banana diseases. Although less damaging than black sigatoka, yellow sigatoka (Pseudocercospora musae) still prevails in some regions. This study aimed at testing the hypothesis of light interference in monocyclic parameters of yellow sigatoka epidemics. Grande Naine plantlets kept under contrasting shading conditions had their leaves 1 and 2 inoculated. Evaluations were performed for 60 days. For each inoculated leaf, the time until symptom onset (incubation), presence of infectious lesions (latency), and disease severity (extensive leaf necrosis) according to Stover's scale modify per Gauhl (1994), called here only Stover's scale, were registered. Logistic regression was used to assess the relative occurrence risk and survival analysis was used to check the effects of variables on relevant epidemiological parameters. The risks of sporulation and of reaching high severities were lower for plants kept under shading regardless of the acclimation conditions and no effect of leaf age was detected. The logistic regression showed symptoms appearing in both conditions $(p=0,85)$, but have significance difference in occurrence of latent lesions $(p=0,013)$ and necrosis $(p<0,0001)$. The necrosis risk in non-shaded environment arrived $66 \%$. The survival analysis showed significance difference in the time to appear the symptom evaluated in all tested variables $(p<0,0001)$ in function of the cropping system. Lower illuminance negatively affected the incubation, latency and infectious periods, and severity. A shaded system could be tested to produce organic bananas in areas of high risk of occurrence of Yellow sigatoka disease.

\section{INTRODUCTION}

Sigatoka leaf spot (popularly known as Yellow Sigatoka) is a Musa sp. fungal disease caused by Pseudocercospora musae (syn. Mycosphaerella musicola) (Carlier et al., 1994). This disease is found in most banana growing regions of the world (Mourichon, 2002; Crous et al., 2003) and although is not more severe than black Sigatoka (black leaf streak) caused by $P$. fijiensis (syn. $M$. fijiensis) (Mourichon, 2002; Fullerton, 1994; Jones, 
2000 apud Marín et al., 2003; Churchill, 2011), it can still cause considerable losses at higher altitudes and cooler temperatures, and is also typically a greater problem during rainy seasons in subtropical banana growing regions (Mouliom-Pefoura et al. 1996). The disease reduces the leaf's photosynthetic capacity, which affects bunch size. It also shortens the fruit's green life and the time between harvest.

Despite both pathogens occurring in Brazil, P. musae is more disseminated and responsible to decrease the banana yield in the field (Gomes et al., 2013: Silveira et al., 2016). The pathogen infect through stomata, mainly on the three younger leaves, although infection may occur on the fourth leaf in case of severe outbreaks (Agrios, 2005). The first symptoms appear three to four weeks after spores land on susceptible leaf surfaces (Hoss et al., 2000). These diseases have an endemic nature in tropical countries and epidemics may occur depending on local climatic conditions and the adopted crop management (Fourè, 1994). The main environmental factors influencing infection, inoculum production and dissemination are temperature, rain and dew (Cordeiro et al., 2004). These factors can also affect the incubation period (Cordeiro, 1997), the latent period (Marin et al., 2003) and the development of lesions (Fourè, 1994).

Banana cultivation in a semi-shaded scheme, as agroforestry systems or under high density, is thought to be an alternative cropping system to manage Yellow Sigatoka. Studies on black Sigatoka show that for plants grown under nylon shading meshes (30\% light) there is a significant decrease in the disease's incidence and a slower disease development than at $70 \%$ of light (Norgrove, 1998; Favreto et al., 2007; Dold et al., 2008; Beltrán-García et al., 2014). In low-density plantations (16002500 plants/ha), removal of old infected leaves leads to a $16 \%$ reduction in disease incidence and $10 \%$ in severity, but at high densities (3333 plants/ha), where there is more shade, incidence was not affected and severity was reduced by $18 \%$ (Emebiri \& Obiefuna, 1992).
This shows that the light level could be interfering in the fungal life cycle.

The lower black Sigatoka severity registered under shade conditions was hypothesized to correlate with a diminished activation of the pathogen's toxin cercosporin and lower amounts of reactive oxygen species generated by melanin in the shade (Daub et al., 2005; Beltrán-García et al., 2014). Furthermore, the light also has been shown to influence the $P$. fijiensis sporulation (Sepúlveda et al., 2009).

Shade is also supposed to limit damages caused by $P$. musae (Vivan, 2002), but no detailed studies have been carried out for yellow Sigatoka. Soon, this is an excellent opportunity to study the relation between the illuminance, amount of light per unit area, and the Yellow Sigatoka life cycle.

The objective of this study was to assess light interference with epidemiological parameters of yellow Sigatoka. A hypothesis of light-dependent Sigatoka was tested by characterizing the risks of infection, sporulation and leaf necrosis in inoculated plants. The hypothesis of light-enhanced Sigatoka was tested by quantifying the length of incubation, latency, and infectious periods. The light-dependent hypotheses admit that the variables occurs in the illuminated environmental and not in the shade. On the other hand, the light-enhanced hypotheses admit that the variable occurs in two situations, illuminated or shaded environmental, and that the light makes increase and shade decrease in the time of development of disease.

\section{MATERIALS AND METHODS}

Banana plantlets (before Musa paradisiaca L. var. Grand Naine, now Musa acuminate L. var. Grande Naine) were produced in vitro (Campo, Cruz das Almas, Bahia). Then, half of plantlets were acclimated at full sun and the other half under $50 \%$ light.

After 130 days of cultivation the plantlets were taken to shade house to inoculation and start the experiment. The shade house was $2 m$ high and covered with a dark nylon screen (Sombrite 75\%). The roof was fixed, but the 
sides were built with rolling screens. The side screens were rolled up every night and in periods during the day when sunlight could not directly reach the plants. Hence, minimizing differences in temperature, relative humidity and leaf wetness between shaded and nonshaded areas. Before inoculation, stomata density was determined right before fungal inoculations by pressing a glass slide covered with a thin layer of Loctite adhesive on the leaves surface for 2". The adhesive layer was examined under a microscope at $10 \mathrm{X}$ and the number of stomata per area determined.

The inoculation was done with the isolate CNPMF $06 / 10$ of $P$. musae, obtained from the municipality of Muritiba, Bahia and deposited in the Embrapa Cassava \& Fruits culture collection, was used in all inoculations. Spores were produced according to Cordeiro et al (2011). Spore suspensions were adjusted to 4 x $10^{4}$ conidia/mL and used to spray leaves 1 and 2 until run-off; non-inoculated plants were sprayed with sterile water. The numbering of the banana leaves starts from the youngest leaf, with the number zero, which is still curled, followed by the older leaves 1, 2, and so on, which are already totally Unrolled. Inoculations took place at dusk to prevent illuminance effects in the pre-penetration processes. All plants were covered with plastic bags after inoculation and kept under shading overnight. The non-inoculated leaves was used to check the natural infections from environmental.

Fourteen hours after the inoculation the plastic bags were removed. The plantlets were arranged in completely randomized blocks, with four groups: T1) plantlets kept under full sun and acclimated in the sun; T2) plantlets kept under sun and acclimated in the shade; T3) plantlets kept under shade and acclimated in the sun, and T4) plantlets kept in the shade and acclimated in the shade. Due to plant losses during acclimation, the experimental groups were different for each treatment. T1 and T3 had 60 inoculated and 40 noninoculated plantlets; T2 had 60 inoculated and 19 non-inoculated plantlets, and T4 had 40 inoculated and 19 non-inoculated plantlets. Groups T3 and T4 we kept in the shade house whereas the other two were kept in an adjoining area the same size as the shaded one.

Every eight days disease severity was evaluated with the aid of a scale described by Stover modify per Gauhl (1994), where (0) represents no symptoms; (1) less than $1 \%$ of the leaf tissue lesioned or a maximum of 10 lesions; (2) 1 to $5 \%$ of lesioned leaf tissue; (3) 6 to $15 \%$ of lesioned area; (4) 16 to $33 \%$; (5) 34 to $50 \%$; (6) 51 to $100 \%$; (-) dead necrotic leaf hanging on the pseudostem. Leaves number 1 and 2 were evaluated daily for the following variables: occurrence of the first lesion (incubation period); occurrence of the first sporulating lesion (latent period) observing gray lesions, number of days to reach disease index 4 according to the scale (severity), number of days to reach the dash index (necrosis). The infectious period was defined as the time between latency and necrosis and illuminance as the amount of light casting in a determined area. Three explanatory variables were tested: (1) shade conditions during acclimation; (2) shade conditions after inoculation; (3) age of the inoculated leaf (number 1 or 2 ).

The illuminance (lux, luminous power incident on a surface) was measured daily at noon in at least four positions of each contrasting areas using a photometer. Temperature was also registered daily in shaded and non-shaded areas.

Due to the longitudinal nature of the experiment, different groups sizes, and occurrence of censored data, we used survival analysis (Statistical release program 7.1) and logistic regression as statistical tools. The logistic regression (BioEstat 5.0) was applied to model the risk imposed by the explanatory variables to the occurrence of an event. In this case, both explanatory and dependent variables are binary [e.g. shade (0) or noshade (1) versus no symptoms (0) or symptoms (1)]. The events of interest were the presence of symptoms, the presence of sporulating lesions, occurrence of high severities (level 4 in the Stover's scale) and occurrence of extensive leaf necrosis (level 6). 
The coefficients of each regression were calculated using maximum likelihood. A given model was accepted only when the regression and the coefficients were statistically significant $(p<0.05)$. The odds ratio (probability of occurrence: probability of non-occurrence) was calculated for each significant explanatory variable.

Survival analysis was used to model the time to the events of interest. Here, we considered the incubation period, the latency period, and the time to disease development, to high severities and to necrosis, as defined above. The proportional hazards model was fitted to the data, and its adequacy was tested by $x^{2}$ test. A model was accepted only when the coefficients of the explanatory variables were significant $(p<0.05)$. Hazards ratios werecalculated for each of them. KaplanMeyer curves (Statistical release 7.1) were constructed for each combination of significant explanatory variables, and used to estimate the median expectancy of each epidemiological period of interest.

\section{RESULTS}

Illuminance, Temperature and Stomatal density. The illuminance under shaded conditions was approximately $26 \%$ of that registered at the non-shaded area (Figure 1). The mean of stomatal density of plants acclimated under shading was $38.5 \pm 6.4$ stomata per $\mathrm{mm}^{2}$ whereas it was $50.8 \pm 8.5$ stomata per $\mathrm{mm}^{2}$ for those acclimated under the sun. The temperature under the shading apparatus was $30.1 \pm 2.5$ and $27.6 \pm 1.1$ at the non-shaded area. The difference in the median values to both stomata and temperature were significant ( $p<0.001$ ) according the MannWhitney statistical test. In the shaded area we observed lower number of stomata/ $/ \mathrm{mm}^{2}$ and higher temperature averages, while in the sunny area we had more stomata/ $/ \mathrm{mm}^{2}$ and lower temperature averages.



Figure 1. Illuminance values \pm standard error along the experiment for the shaded and the non-shaded experimental areas. 
Experimental data. The inoculated leaves maintained under full sun had the time of incubation, latency, and to reach severity 4 and 6 less than those under shade (Table 1). All epidemiological parameters evaluated occurred earlier in plants grown in the sun than in plants grown in the shade (Table 2). The percentage of plants that completed their incubation period at the end of the experiment was equal, but these percentages were higher for plants completing the latency and infectious periods, and for plants that reached severity 4 and 6 (Table 2). These data were subjected to modelling with two different approaches: logistic regression and survival analysis.

Light-dependent hypothesis. The logistic regression determines the relationship between the occurrence of one epidemiological event and the independent variables at the end of the experiment. It shows the chance of leaves showing an event under one or another system. The logistic regression was not significant for the incubation period when the variables acclimation, growth system and leaf number were considered $(p=0.85)$. Likewise, latent period, time to severity 4 and time to severity 6 were not significant when the model considered the effect of the variables acclimation, growth system and leaf number together. However, a simpler model that took into account only the variable growth system was significant (Table 3). The latent period for plants grown in the sun have a risk $4 \mathrm{X}$ higher to produce sporulated lesions than plants grown in the shade (Table 3 ).

The effect of growth system was significant for the occurrence of lesions on $16-33 \%$ of the leaf area (severity index 4 according to Gauhl's scale) and necrosis (severity index 6) according to the multiple logistic regression $(p<0.0001)$. The risk of occurring severity index 4 was 6X higher for non-shaded plants. Considering the occurrence of severity index 6 , the risk was $66 \mathrm{X}$ higher for non-shaded plants (Table 1).
Light-enhanced hypothesis. The survival analysis determines the effect of the explanatory variables at each day until the occurrence of the event of interest. Such analysis was used to quantify the delay in the epidemiological periods. The interference of illuminance on incubation and latency periods was significant for acclimation and growth system according to Cox's model of proportional risks (Table 4). The probabilities of a shorter incubation period (1.3X) and a shorter latency period (1.4X) are higher for non-shaded acclimated plants. The risk of shorter incubation period (2.2X) and a shorter latency period (2.5X) are higher for plants grown in non-shaded area (Table 4).

The Kaplan-Meyer (KM) curves show the real data with the adjusted models and allow the medians to be calculated. Treatments combining sun-sun (acclimation-growth system), shade-sun and sun-shade, $90 \%$ of the plants showed symptoms before 42 days after the inoculation, whereas treatments combining shade-shade the first symptoms appeared after 51 days (Figure 2A). At the end of the experiment, $80 \%$ of the shade-shade (acclimation-growth system) plants and 90\% of sun-shade and sun-sun plants showed sporulated lesions according to the KM curves (Figure 2B).

There was an influence of the growth conditions on the time to reach severity 4 and severity 6 (necrosis). According to Cox's model of proportional risks, non-shaded have a $3.3 \mathrm{X}$ higher chance of showing lesions on $16-33 \%$ of the leaf area than shaded grown plants. Similarly, the chance of showing more than $50 \%$ of lesioned leaf area is $21 \mathrm{X}$ higher for non-shaded grown plants (Table 4).

The KM curves showed that 36 days was required for the first non-shaded grown plants to present severity 4 , whereas it took 44 days for shaded plants. The model for growth system (Figure 2D) shows that under shade $10 \%$ of the plants had the infectious period defined and $90 \%$ of the plants grown in the sun had lesions with the infectious period defined. 
bioRxiv preprint doi: https://doi.org/10.1101/828848; this version posted November $2,2019$. The copyright holder for this preprint (which was not certified by peer review) is the author/funder, who has granted bioRxiv a license to display the preprint in perpetuity. It is made available under aCC-BY-NC-ND 4.0 International license.

Table 1. Average number of days for the occurrence of epidemiological events in plants acclimated and grown in the sun or in the shade.

\begin{tabular}{lccccc}
\hline \multicolumn{1}{c}{ Epidemiological event } & & \multicolumn{2}{c}{ Growth system - sun } & \multicolumn{2}{c}{ Growth system - shade } \\
\hline & $\begin{array}{c}\text { Leaf } \\
\text { age }\end{array}$ & Acclimation - sun & $\begin{array}{c}\text { Acclimation - } \\
\text { shade }\end{array}$ & Acclimation - sun & Acclimation - shade \\
\hline \multirow{3}{*}{ Incubation period } & F1 & 25.1 & 27.1 & 30.8 & 30.3 \\
& F2 & 26.1 & 28.8 & 31.4 & 33.2 \\
\hline \multirow{3}{*}{ Latency period } & Mean & 25.6 & 27.9 & 31.1 & 31.8 \\
& F1 & 30.0 & 32.7 & 37.1 & 38.2 \\
\hline \multirow{3}{*}{ Severity 4 } & F2 & 30.5 & 35.1 & 38.6 & 40.7 \\
\hline \multirow{2}{*}{ Severity 6 } & Mean & 30.3 & 33.9 & 37.8 & 39.4 \\
& F1 & 37.4 & 40.7 & 48.0 & 47.0 \\
\hline & F2 & 38.0 & 40.7 & 46.8 & 47.3 \\
\hline & Mean & 37.7 & 40.7 & 47.4 & 47.2 \\
\hline & F1 & 26.4 & 30.3 & 59.7 & 59.4 \\
\hline & F2 & 29.5 & 31.7 & 59.1 & 58.5 \\
\hline
\end{tabular}

Table 2. Days for the onset of the epidemiological events and percentage of plants with symptoms at 60 days to sun and shade conditions.

\begin{tabular}{|c|c|c|c|c|}
\hline \multirow{3}{*}{ Event } & \multicolumn{2}{|c|}{$\begin{array}{l}\text { Days for the onset of the } \\
\text { epidemiological events }\end{array}$} & \multicolumn{2}{|c|}{$\begin{array}{l}\text { Percentage of plants with } \\
\text { symptoms at } 60 \text { days }\end{array}$} \\
\hline & & & & \\
\hline & Sun & Shade & Sun & Shade \\
\hline Incubation period & 20 & 26 & 99 & 99 \\
\hline Latency period & 23 & 33 & 99 & 90 \\
\hline Severity 4 & 36 & 43 & 90 & 58 \\
\hline Severity 6 & 43 & 52 & 79 & 5 \\
\hline Infectious period & - & - & 89 & 6 \\
\hline
\end{tabular}

Table 3. Logistic regression showing significance $(P)$, and the significance and odds ratio of each explanatory variable for two events related to epidemiological parameter (occurrence of symptoms and sporulating lesions) and two severity related events. Leaf type and pre-inoculation conditions were non-significant whereas post-inoculation conditions was significant for all but the occurrence of symptoms. Leaves from plants kept non-shaded had more than $6 x$ the chance of reaching Stover 4 than those on shaded plants.

\begin{tabular}{|c|c|c|c|c|c|}
\hline \multirow[t]{2}{*}{ Event } & \multirow[t]{2}{*}{$\mathrm{P}$} & \multirow[t]{2}{*}{ Equations } & $\begin{array}{c}\text { Acclimatio } \\
n\end{array}$ & Growth system & Leaf age \\
\hline & & & \multicolumn{3}{|c|}{ Odds Ratio } \\
\hline Incubation period & $0.85^{\mathrm{ns}}$ & Logit $\mathrm{Pi}=3.28+(0.28 \mathrm{X} 1)+(0.66 \mathrm{X} 2)+(0.016 \mathrm{X} 3)$ & $1.33^{\mathrm{ns}}$ & $1.95^{\mathrm{ns}}$ & $1.02^{\mathrm{ns}}$ \\
\hline Latency period & $0.013^{*}$ & Logit $\mathrm{Pi}=2.30+(1.38 \times 1)$ & $1.30^{\mathrm{ns}}$ & $3.97^{*}$ & $0.73^{\text {ns }}$ \\
\hline Severity 4 & $<0.0001^{*}$ & Logit $\mathrm{Pi}=0.28+(1.84 \mathrm{X} 1)$ & $0.76^{\mathrm{ns}}$ & $6.31^{*}$ & $1.40^{\mathrm{ns}}$ \\
\hline Severity $>6$ & $<0.0001^{*}$ & Logit $\mathrm{Pi}=-2.93+(4.19 \times 1)$ & $1.07^{\mathrm{ns}}$ & $66.15^{\star}$ & $1.37^{\mathrm{ns}}$ \\
\hline
\end{tabular}

Table 4. Results of Cox's proportional hazards regression (survival analysis) showing the significance and the estimated hazard ratio of each explanatory variable for three epidemiological parameters (incubation, latency and infectious periods) and two severity events. Leaf type had no effect on the time until the events, whereas pre-inoculation conditions affected only the latency period. Post-inoculation conditions affected the times to all events (e.g. non-shaded leaves reach Stover 4 severity 3.28x faster than shaded ones).

\begin{tabular}{|c|c|c|c|c|}
\hline \multirow[t]{2}{*}{ Event } & \multirow[t]{2}{*}{ Equations } & Acclimation & Cropping system & Leaf age \\
\hline & & \multicolumn{3}{|c|}{ Hazard ratio $(p)$} \\
\hline Incubation period & {$\left[\mathrm{h}(\mathrm{t})=\mathrm{h} 0(\mathrm{t}) \exp ^{\left(0.27^{*} \text { acclimation }+0.80^{*} \text { growth system }\right)}\right]$} & $1.29(p=0.03)$ & $2.24(p<0.000)$ & $0.86(p=0.17)$ \\
\hline Latency period & {$\left[\mathrm{h}(\mathrm{t})=\mathrm{h} 0(\mathrm{t}) \exp \left(0.35^{*}\right.\right.$ acclimation $+0.92^{*}$ growth system $\left.)\right]$} & $1.41(p=0.004)$ & $2.51(p<0.000)$ & $0.82(p=0.08)$ \\
\hline Severity 4 & $h(t)=h 0(t) \exp ^{\left(1.17^{*} \text { growth system }\right)}$ & $1.09(p=0.53)$ & $3.28(p<0.000)$ & $1.08(p=0.56)$ \\
\hline Severity $>6$ (full necrosis) & $h(t)=h 0(t) \exp ^{\left(3.06^{*} \text { growth system }\right)}$ & $0.95(p=0.79)$ & $21.11(p<0.000)$ & $1.21(p=0.33)$ \\
\hline Infectious period & $h(t)=h 0(t) \exp ^{\left(2.86^{*} \text { growth system }+0,44^{*} \text { leaf number }\right)}$ & $0.69(p=0.06)$ & $17.11(p<0.000)$ & $1.64(p=0.01)$ \\
\hline
\end{tabular}


bioRxiv preprint doi: https://doi.org/10.1101/828848; this version posted November 2,2019 . The copyright holder for this preprint (which was not certified by peer review) is the author/funder, who has granted bioRxiv a license to display the preprint in perpetuity. It is made available under aCC-BY-NC-ND 4.0 International license.

The infectious period was influenced by growth system $(p<0.0001)$ and leaf age $(p=0.015)$, but only marginally by acclimation $(p=0.064)$. The model of proportional risks of
Cox, showed a risk 17X higher of occurring the infectious period for non-shaded grown plants and 1.6X higher for leaves number 2 than for leaves number 1.
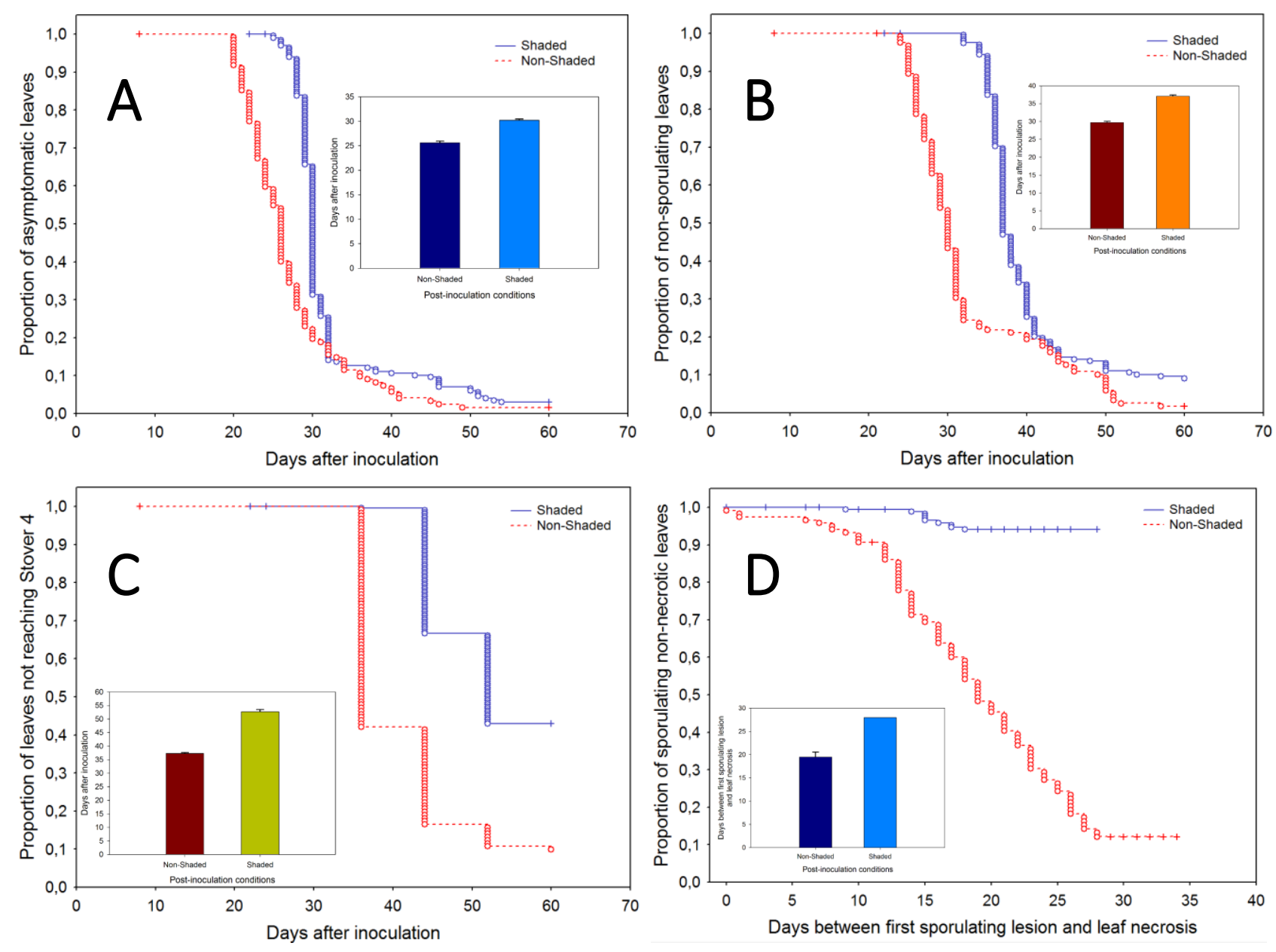

Figure 2. Kaplan-Meyer curves under shaded (blue) and non-shaded (red) post-inoculation conditions for incubation period (A), latency period (B), time to severity Stover 4 (C) and infectious period (D) of yellow Sigatoka. The insets show the median expected time \pm standard error of each parameter under the two post-inoculation conditions. Circles represent complete observations and the crosses represent the censored observations. As less the half of the shaded leaves were necrotic at experiment completion, the related infectious period estimate is not precise. Note that the difference between shaded and non-shaded conditions is progressive (incubation: 4.6 days, latency: 7.4 days, Stover 4: 15.5 days). The results are consistent with the hypothesis of light-activated phytotoxins affecting the colonization process. On the other hand, the shorter latency on non-shaded leaves can influence the reproduction process. 


\section{DISCUSSION}

The methodologies we used to study yellow Sigatoka disease were able to explain its behaviour in shaded and non-shaded systems. With the logistic regression analysis we calculate the risk of the pathogen present the incubation, latency or different levels of severity on shaded or non-shaded systems. The survival analysis was used to quantify the delay on the incubation, latency and different levels of severity. The first analysis was used to check if the variable occurs or not in function of illuminance, and the second one to compare and explain the behaviour of the variable, when it appear in shaded and non-shaded enviromental, over the time. These new approach are applied generally in medicine, engineering and others area, and are excellent tool to have better explanation about sigatoka behaviour.

The incubation period determined experimentally in this study was similar to values found by other authors, such as 13 to 31 days (Marín et al., 2003) and 24.8 days at $30^{\circ} \mathrm{C}$ (Rocha, 2012). The occurrence of the disease was not influenced by the acclimation, growth system nor leaf age, confirming that the disease occurs in both shaded and nonshaded plants. However, the data show differences in the time for appearance of lesions in the different growth systems.

The longer incubation period for shaded grown plants indicates that illuminance interferes in fungal penetration and colonization. In fact, laboratory experiments (Santana-Filho et al., 2012) showed that illuminance decreases mycelial growth and spore germination. The explanation for the longer incubation is the possible lower production of phytotoxins and other pathogenesis-related compounds lightdependent, as suggested by Stierle et al. (1991), Daub et al. (2005) and Beltrán-García et al. (2014). On shade these compounds are not produced, affecting the epidemiological parameters penetration and colonization. Nevertheless, one study showed that there is no relation between light and phytotoxins produced by Pseudocercospora fijiensis (Cruz-
Cruz et al., 2009). Further studies need to be conducted to shed light on this important aspect of the plant-pathogen relationship.

The effect of stomata density and infection by $P$. musae is not well understood. In this study, the leaves with high stomata density had short incubation time as the results showed by Craenem et al. (1997) that found negative correlation between Black Sigatoka incubation time and stomata density on polyploid hybrids.

The time for the appearance of the first sporulated lesions (latency) was similar to data found by other authors. For example, 46 days at $20^{\circ} \mathrm{C}, 32$ days at $24^{\circ} \mathrm{C}$ and 33 days at $30^{\circ} \mathrm{C}$ in plantations of Saquarema variety, Cavendish (AAA) subgroup located in Minas Gerais, Brazil (Rocha, 2012), and 26 to 42.5 days for varieties Nanicão e Prata Anã in plantations of Bahia, Brazil (Cordeiro, 1997). Santana-Filho et al. (2012) show that low amounts of light reduce sporulation of $P$. musae, corroborating data from Sepúlveda et al. (2009).

The time to reach severity indices 4 and 6 was decreased in non-shaded grown plants, which is in agreement with reports affirming that growing banana in the shade may reduce the damage caused by black sigatoka (Norgrove, 1998, Norgrove et al. 2012, Norgrove \& Hauser, 2012).

The infectious period is shorter in plants grown in the sun, but these plants produce more lesions and more spores as a result of the illuminance effect. In summary, illuminance influences all stages of the pathogen's life cycle, and this study shown that from acclimatization, age from leaves and growth system, the last one was the most important variable influencing disease development. Whitin one year, according to the data analyzed, we have 10,72 cycles of latency in the Sun and 7,63 cycles in the shade condition. The same situation was found to severity $4(5,49$ cycles/year in the sun; 4,60 cycles/year in the shade) and severity $>6(1,99$ cycles/year in the sun; 1,65 cycles/year in the shade). The data analyzed shows complete infection periods to $89 \%$ of plats in the sun in 
60 days, so then in a year we could have 6 complete cycles for $89 \%$ of plants. In the shade conditions only $6 \%$ of plants could be have the same situation described above.

Differently from other studies, we reported the risks for the occurrence of different epidemiological events and the exact time they happened. The data may be used in the construction of parameters to model the temporal dynamics of yellow Sigatoka disease, which remains the most important foliar disease in Brazil. Our studies have shown that crop systems with shaded enviromental as agroforestry systems is better to banana cultivation because is the best cultural way to control the pathogen reproduction and dissemination.

\section{ACKNOWLEDGEMENTS}

The authors are grateful to CNPq for their research grant. We also thank Mr Francisco Paulo dos Santos Souza (Embrapa Cassava\&Fruits) for his technical assistance. DMSF is indebted to CAPES for scholarship in the master degree and Master Program in Agricultural microbiologist of UFRB for study opportunity. FFL is indebted to $\mathrm{CNPq}$ for his research grant.

\section{REFERENCES}

Agrios GN (2005) Plant Pathology. $5^{\text {th }}$ Ed. Amsterdam, The Netherlands. Elsevier Academic Press.

Beltrán-García MJ, Prado FM, Oliveira MS, OrtizMendoza D, Scalfo AC, Pessoa JRA, Medeiros MHG, White JF, Di Mascio P (2014) Singlet molecular oxygen generation by light-activated DHN melanin of the fungal pathogen Mycosphaerella fijiensis in Black Sigatoka Disease of bananas. PLOS One 3:9-15. Doi: 10.1371/journal.pone.0091616.

Carlier J, Mourichon X, Gonzáles-De-Leon D, Zapater MF and Lebrun MH (1994) DNA restriction fragment length polymorphisms in Mycosphaerella species that cause banana leaf spot diseases. Phytopathology 84:751-756.

Churchill ACL (2011) Mycosphaerella fijiensis, the black leaf streak pathogen of banana: progress towards understanding pathogen biology and detection, disease development, and the challenges of control. Molecular plant pathology 12:307-28. Doi: 10.1111/J.13643703.2010.00672.X.

Cordeiro ZJM (1997) Variabilidade patogênica de isolados de Mycosphaerella musicola e resistência induzida e genética em bananeiras. PiracicabaSP, Brazil: Escola Superior de Agricultura Luiz de Queiroz, PhD thesis.

Cordeiro ZJM, Matos AP, Meissner-Filho PE (2004) Doenças E Métodos de Controle. In: Borges AL, Souza LS. O Cultivo da Bananeira. EMBRAPA. Cruz das Almas, 146-182.

Cordeiro ZJM, Rocha HS, Araújo AG (2011) Metodologia para manuseio de Mycosphaerella musiocola em laboratório. Cruz das Almas-BA, Brazil: Embrapa Mandioca e Fruticultura.

Craenen K, Coosemans J, Ortiz R (1997) The role of stomatal traits and epicuticular wax in resistence to Mycosphaerella fijiensis in banana and plantain (Musa spp.). Tropicultura 15:136-40.

Crous PW, Groenewald JZ, Aptroot A, Braun U, Mourichon X, Carlier J (2003) Integrating morphological and molecular data sets on Mycosphaerella, with specific reference to species occurring on Musa. In: Jacome L, Lepoivre P, Marín D, Oriz R, Romero R, Escalant JV, eds. Proceedings of the Workshop on Mycosphaerella Leaf Spot Diseases, 2002. San José, Costa Rica, 43-57.

Cruz-Cruz CA, García-Sosa K, Escalante-Erosa F, Peña-Rodríguez LM (2009) Production of hydrophilic phytotoxins by Mycosphaerella fijiensis. Journal of General Plant Pathology 75:191 - 95.

Daub ME, Herrero S, Chung K (2005) Photoactivated perylene quinone toxins in fungal pathogenesis of plants. FEMS Microbiology Letters 252:197-206.

Dold C, Staver C, Pocasangre L, Heller J (2008) Musa in Shaded Perennial Crops - Response to Light Interception. In: Conference on International Research on Food Security, Natural Resource Management and Rural Development. Stuttgart, Germany, 1-4.

Emebiri LC, Obiefuna JC (1992) Effects of leaf removal and intercropping on the incidence and severity of black Sigatoka disease at the establishment phase of plantains (Musa spp. AAB). 
Elsevier Science Publishers, Agriculture, Ecosystems and Environment 39:213-19.

Favreto R, Model NS, Tonietto A (2007) Sigatoka Negra, fatores do ambiente e sistemas agroflorestais em bananais do Rio Grande do Sul, Brasil. Pesquisa Agropecuária Gaúcha 13:95-104.

Fourè $E$ (1994) Leaf spot diseases of banana and plantain caused by Mycosphaerella musicola and M. fijiensis. In: The Improvement and Testing of Musa: A Global Partnership. Montpellier, France, 37-46.

Gauhl F (1994) Epidemiology and Ecology of black Sigatoka (Mycosphaerella fijiensis Morelet) on Plantain and Banana (Musa spp.) in Costa Rica, Central America. Montpellier, France. INIBAP.

Gomes LIS, Douhan GW, Bibiano LBJ, Maffia LA, Mizubuti ESG (2013) Mycosphaerella musicola identified as the only pathogen of the Sigatoka disease complex present in Minas Gerais State, Brazil. Plant Disease 97:1537-43. Doi: 10.1094/PDIS-12-12-1212-RE.

Hoss R, Helbig J, Bochow H (2000) Function of host and fungal metabolites in resistance response of banana and plantain in the black Sigatoka disease pathosystem (Musa spp.-Mycosphaerella fijiensis). Jornal of Phytopathology 148:387-94. Doi: 10.1046/j.1439-0434.2000.00530.x.

Marín, DH, Romero RA, Guzmán M, Sutton TB (2003) Black Sigatoka: An Incresing Threat to Banana Cultivation. Plant Disease 87.

Mouliom-Pefoura A, Lassoudière A, Foko J, Fontem DA (1996) Comparison of development of Mycosphaerella fijiensis and Mycosphaerella musicola on banana and plantain in the various ecological zones in Cameroon. Plant Disease 80:950-954.

Mourichon X (2002) Overview of progress and results since the first international workshop on Mycosphaerella leaf spot diseases of bananas in 1989. In: Jacome L, Lepoivre P, Marín D, Ortiz R, Romero R, Escalant JV, eds. Proceedings of the 2nd International workshop on Mycosphaerella leaf spot diseases held. San José, Costa Rica, 11-18.

Norgrove L (1998) Musa in multistrata systems: focus on shade. Infomusa 7:17-22.
Norgrove L, Hauser S (2012) Black leaf streak disease and plantain fruit characteristics as affected by tree density and biomass management in a tropical agroforestry system. Agroforestry Systems 71:1-8.

Norgrove L, Tueche JR, Jacobsen KS, Attey NA, Holmes K (2012) Tackling black leaf streak disease and soil fertility constraints to enable the expansion of plantain production to grassland in the humid tropics. International journal of pest management 58:175-81.

Rocha HS, Pozza EA, Uchoa CN, Cordeiro ZJM, Souza PE, Sussel AAB, Rezende CA (2012) Temporal Progress of Yellow Sigatoka and Aerobiology of Mycosphaerella musicola Spores. Jornal of Phytopathology 160:277-85.

Santana-Filho DM (2012) Influência da Luz em Parâmetros Epidemiológicos da Sigatoka-Amarela da Bananeira. Cruz das Almas, Brazil: Universidade Federal do Recôncavo da Bahia, Masters dissertation.

Sepúlveda L, Vásquez LE, Paniagua CI, Echeverry $D$, Hernández CA, Rodríguez E, Restrepo LF, Arango $R$ (2009) The presence and spectrum of light influences the in vitro conidia production of Mycosphaerella fijiensis causal agent of black Sigatoka. Australasian Plant Pathology 38:514-17.

Silveira OR, Bagolin DJ, Neto DC, Martins MB, Silvas RM, Araújo JAN (2016) Distribution of black leaf streak disease (Mycosphaerella fijiensis Morelet) in Mato Grosso, Brazil. Bioscience Journal 32:384-88. Doi: 10.14393/BJv32n2a2016-31359.

Stierle AA, Upadhyay R, Hershenhorn J, Strobel GA, Molina G (1991) The phytotoxins of Mycosphaerella fijiensis, the causative agent of Black Sigatoka disease of bananas and plantains. Birkhfiuser Verlag, Switzerland: Experientia 47:853-59.

Vivan JL (2002) Bananicultura em Sistemas Agroflorestais no Litoral Norte do RS. Agroecologia e Desenvolvimento Rural Sustentável 3. 